\title{
Spatio-temporal variation in transpiration responses of maize plants to vapor pressure deficit under an arid climatic condition
}

\author{
ZHAO Wenzhi ${ }^{1,2^{*}}$, JI Xibin ${ }^{1,2}$ \\ ${ }^{1}$ Linze Inland River Basin Research Station, Chinese Ecosystem Network Research, Lanzhou 730000, China; \\ ${ }^{2}$ Key Laboratory of Ecohydrology of Inland River Basin, Cold and Arid Regions Environmental and Engineering Research \\ Institute, Chinese Academy of Sciences, Lanzhou 730000, China
}

\begin{abstract}
The transpiration rate of plant is physically controlled by the magnitude of the vapor pressure deficit (VPD) and stomatal conductance. A limited-transpiration trait has been reported for many crop species in different environments, including Maize (Zea mays L.). This trait results in restricted transpiration rate under high VPD, and can potentially conserve soil water and thus decrease soil water deficit. However, such a restriction on transpiration rate has never been explored in maize under arid climatic conditions in northwestern China. The objective of this study was to examine the transpiration rate of field-grown maize under well-watered conditions in an arid area at both leaf and whole plant levels, and therefore to investigate how transpiration rate responding to the ambient VPD at different spatial and temporal scales. The transpiration rates of maize at leaf and plant scales were measured independently using a gas exchange system and sapflow instrument, respectively. Results showed significant variations in transpiration responses of maize to VPD among different spatio-temporal scales. A two-phase transpiration response was observed at leaf level with a threshold of $3.5 \mathrm{kPa}$ while at the whole plant level, the daytime transpiration rate was positively associated with VPD across all measurement data, as was nighttime transpiration response to VPD at both leaf and whole plant level, which showed no definable threshold vapor pressure deficit, above which transpiration rate was restricted. With regard to temporal scale, transpiration was most responsive to VPD at a daily scale, moderately responsive at a half-hourly scale, and least responsive at an instantaneous scale. A similar breakpoint (about $3.0 \mathrm{kPa}$ ) in response of the instantaneous leaf stomatal conductance and hourly canopy bulk conductance to VPD were also observed. At a daily scale, the maximum canopy bulk conductance occurred at a VPD about $1.7 \mathrm{kPa}$. Generally, the responsiveness of stomatal conductance to VPD at the canopy scale was lower than that at leaf scale. These results indicate a temporal and spatial heterogeneity in how maize transpiration responses to VPD under arid climatic conditions. This could allow a better assessment of the possible benefits of using the maximum transpiration trait to improve maize drought tolerance in arid environment, and allow a better prediction of plant transpiration which underpin empirical models for stomatal conductance at different spatio-temporal scales in the arid climatic conditions.
\end{abstract}

Keywords: maize; limited transpiration trait; gas exchange; sap flow; stomatal conductance; vapor pressure deficit

Citation: ZHAO Wenzhi, JI Xibin. 2016. Spatio-temporal variation in transpiration responses of maize plants to vapor pressure deficit under an arid climatic condition. China. Journal of Arid Land, 8(3): 409-421. doi: 10.1007/s40333-016-0082-z

\footnotetext{
*Corresponding author: ZHAO Wenzhi (E-mail: zhaowzh@1zb.ac.cn)

Received 2015-09-11; revised 2015-10-22; accepted 2015-10-26

(C) Xinjiang Institute of Ecology and Geography, Chinese Academy of Sciences, Science Press and Springer-Verlag Berlin Heidelberg 2016
} 
Agriculture heavily relies on irrigation in the Heixi Corridor area of northwest China (Ji et al., 2006; Kang et al., 2007). Maize is the most important component of local food security. Current agricultural irrigation practices do not promote the sustainable utilization of water resources or the preservation of natural ecosystems in the area (Ji et al., 2006, 2011a). With the prospects of increasing global temperatures and water scarcity in arid regions, efficient agricultural water use is critical (Jones and Thornto 2003; Zhang et al., 2012). Plant characteristics such as enhanced drought tolerance and efficient water use could improve crop productivity (Riar et al., 2015).

One of the key traits to improve maize drought tolerance is to limit transpiration rate under high atmospheric vapor pressure deficit (VPD), which allows a better soil water conservation (Sinclair et al., 2005; Passioura and Angus, 2010; Riar et al., 2015). However, such a restriction on transpiration rate at high VPDs and different spatio-temporal scales has not been documented in maize, especially in arid regions where water is limited; plants and resources that human rely on are scarce, which is a situation commonly found in the arid northwestern China (Chen et al., 2012).

Transpiration through higher-plant stomata is governed by the magnitude of the atmospheric VPD, and by the leaf stomatal conductance (McNaughton and Jarvis, 1991; Jones, 1998; Taiz and Zeiger, 2002). In general, transpiration rates and VPD follow a diurnal pattern, being lowest at sunrise and increasing to maximum around midday (Bunce, 1981; Jarvis and McNaughton, 1986; Jones, 1998; Hirasawa and Hsiao, 1999; Shekoofa et al., 2014). However, the increase of transpiration has limits with a limiting maximum transpiration rate commonly reached at a higher VPD (Grantz, 1990; Franks et al., 1997; Fletcher et al., 2007). The hypothesized mechanism for the limited-transpiration trait is a leaf level hydraulic limitation that results in limited water transport and decreased stomatal conductance at high VPDs (Mott, 2007; Sinclair et al., 2008; Sadok and Sinclair, 2009; Choudhary et al., 2015; Riar et al., 2015). Such limited-transpiration trait at high VPD tends to restrict the photosynthetic rate, thus to increase transpiration efficiency (or water use efficiency), to delay damaging physiological effects of water deficit stress in plant tissues, and to conserve soil water (Sinclair et al., 2005; Yang et al., 2012; Seversike et al., 2013; Shekoofa et al., 2014).

Considerable evidences have confirmed this limited-transpiration trait, even under well-watered conditions in selected genotypes of several crop species including peanut (Arachis hypogaea L., Devi et al., 2010; Shekoofa et al., 2013), sorghum (Sorghum bicolor L., Sinclair et al., 2005; Gholipoor et al., 2010; Shekoofa et al., 2014; Riar et al., 2015), soybean (Glycine max L., Fletcher et al., 2007; Sinclair et al., 2008; Sadok and Sinclair, 2009; Gilbert et al., 2011; Seversike et al., 2013), pear millet (Pennisetum glaucum L., Kholová et al., 2010), wheat (Triticum aestivum L., Rebetzke et al., 2003), and cowpea (Vigna unguiculata L., Belko et al., 2013).

Similarly the limited-transpiration trait in response to increasing VPD has been identified in maize. Hirasawa and Hsiao (1999) reported that when VPD was greater than about $3.5 \mathrm{kPa}$, the epidermal conductance of field-grown maize decreased, possibly in association with a maximum transpiration rate. In pot-grown maize subjected to differing VPD conditions, Ray et al. (2002) found that increase in VPD were not matched by proportional increase in transpiration of young maize plants, indicating essentially a maximum transpiration rate was reached under high VPD conditions. Gholipoor et al. (2013) showed that some maize genotypes exhibited a VPD threshold ranged from 1.7 to $2.5 \mathrm{kPa}$, above which the transpiration rate was restricted. Comparable findings were observed in similar maize genotypic hybrids (Yang et al., 2012; Choudhary et al., 2015).

The limited-transpiration trait at high VPD could result from the stomata sensing and responding to changes in transpiration, i.e. stomatal closure in response to increased transpiration could be a form of negative feedback that optimizes the rate of photosynthesis (Farquhar, 1978; Mott and Parkhurst, 1991; Monteith, 1995; Bunce, 1996; Jones, 1998; Taiz and Zeiger, 2002). However, multiple mutual influences and feedbacks cause interactions among transpiration, stomatal conductance, and the ambient VPD to be complex and non-linear (Jarvis and McNaughton, 1986; McNaughton and Jarvis, 1991; Jones, 1998). Consequently, the transpiration response varies greatly, both among and within species, in response to a wide variety of environmental variables and across different spatio-temporal scales (Jarvis and McNaughton, 1986; McNaughton and Jarvis, 1991; Oren et al., 1999; Bucci et al., 2004; Barbour and Buckley, 2007; Sinclair et al., 2008; Sadok and 
Sinclair, 2009; Mott and Peak, 2010; Gilbert et al., 2011). To demonstrate the interaction of VPD and stomatal conductance in regulating transpiration, it is desirable to measure gas exchange and driving forces simultaneously at both the single leaf and whole plant levels of inquiry (Jarvis and McNaughton, 1986; Collatz et al., 1991; Jones, 1998; Takagi et al., 1998).

The primary objective of the study was to understand the gap in our current understanding of the limited transpiration trait of maize, including the transpiration rate of field-grown maize under wellwatered conditions both at the leaf and whole plant level; and to investigate the differences in transpiration responses to ambient VPD at different spatial and temporal scales. This could allow a better assessment of the possible benefits of using the maximum transpiration trait to improve maize drought tolerance in arid environment, and will be of interest to physiologists, plant breeders and water resources managers. This is also important for predicting the plant transpiration by water resources managers, especially for underpinning empirical models for stomatal conductance at different spatio-temporal scales in arid climatic conditions.

\section{Materials and methods}

\subsection{Site description}

The study site is located in the middle section of Hexi Corridor, Gansu province, northwestern China. We made all field measurements at the agricultural experimental field of the Linze Inland

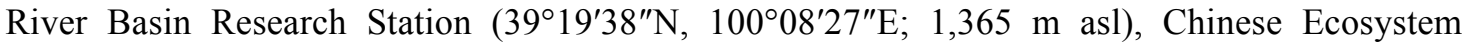
Research Network. The site has a typical continental arid climate, dry and hot in summer, cold in winter. The mean annual precipitation is $117 \mathrm{~mm}$, of which $70 \%$ falls in July to September. The annual mean air temperature is $7.6^{\circ} \mathrm{C}$, with a maximum of $39.1^{\circ} \mathrm{C}$ in July and a minimum of $-27.3^{\circ} \mathrm{C}$ in January. The soil is sandy loam with $59.0 \%$ of sand, $36.3 \%$ of silt and $4.7 \%$ of clay. Soil organic matter content and $\mathrm{pH}$ are $0.72 \%$ and 8.86 , respectively. The detailed information about the site was presented in Ji et al. (2011a, b).

We conducted the study in a maize field (Zea mays L.) planted on 10 April 2011 in $0.45-\mathrm{m}$ rowspacing with a density of about 98,000 plants $/ \mathrm{hm}^{2}$. Throughout the maize growing season, we applied nine flood irrigations for a total of about $1,000 \mathrm{~mm}$ of water (approximately $105 \mathrm{~mm}$ of water for each irrigation) and fertilized at a rate of $326 \mathrm{~kg} \mathrm{~N} / \mathrm{hm}^{2}, 27 \mathrm{~kg} \mathrm{P} \mathrm{O}_{5} / \mathrm{hm}^{2}$, and $17 \mathrm{~kg} \mathrm{~K} / \mathrm{hm}^{2}$, respectively. Thus, crop development throughout the growing season did not suffer from nutrient and/or water stresses, but maintained under well-watered conditions.

\subsection{Methods and measurement}

1.2.1 Meteorological measurements

On a tower (20-m height, six-layer array) within the maize field, we mounted an automatic weather station (IMKO GmbH, Ettlingen, Germany) that continually measured and recorded the 30-minute means of solar radiation, net radiation, air temperature/humidity, air vapor pressure, canopy temperature, wind speed and direction, soil heat flux, soil moisture and temperature, and precipitation throughout the growing season.

1.2.2 Leaf transpiration and stomatal conductance measurements

We simultaneously measured the diurnal $(24 \mathrm{~h})$ values of leaf-level stomatal conductance and transpiration in the field on two sunny (daytime) and clear (nighttime) days (Julian days 188-189 and 218-219) using a portable steady-state gas exchange apparatus (Li-6400 XP, LI-COR Instruments, Lincoln, NE, USA) at approximately hourly intervals on fully expanded leaves. Before the measurement, we enclosed a $6-\mathrm{cm}^{2}$ area of leaf lamina in the instrument chamber and allowed it to equilibrate within the chamber for $60 \mathrm{~s}$ and repeated the measurement for three times. We randomly sampled four leaves from the top, middle and bottom layers of the canopy with 12 observations at each sampling time and then averaged the values to estimate the mean instantaneous leaf conductance and transpiration for each sample at a given time. We maintained the natural inclination and azimuth of the leaves during the measurements. Sampling was always done in the central row of five consecutive rows to avoid any border effect. We took all measurements under 
ambient conditions and recorded the photosynthetically active radiation, leaf temperature, and relative humidity incident on each leaf. Our measurements at leaf scale were taken at 1-h intervals for 24 hours, from morning (as soon as the foliage was entirely dry) until next morning.

\subsubsection{Whole plant transpiration measurements}

We measured whole plant transpiration on six representative plants using the stem heat balance approach (Sakuratani, 1981; Baker and Van Bavel, 1987) during the period from Julian days 189 to 252 , when maize was entering the peak growth, and the soil surface was fully covered by the maize canopy. We installed sap flow gauges (Models SGB 16, SGB 19 and SGB 25, Dynagage, Dynamax Inc., Houston, TX, USA) and graphed the data to confirm that the temperature differences measured by the gauges remained within reasonable bounds.

\subsubsection{Determination of vapor pressure deficit}

Vapor pressure deficit (VPD) was calculated using air temperature and relative humidity was measured using the following equation:

$$
V P D=\left(1-\frac{R H}{100}\right) S V P \text {. }
$$

where $R H$ is the relative air humidity $(\%)$. The saturation vapor pressure $S V P(\mathrm{kPa})$ is calculated from eq. 2 ,

$$
S V P=0.6108 \exp \left(\frac{17.27 T_{a}}{T_{a}+237.3}\right) .
$$

where $T_{a}$ is the air temperature $\left({ }^{\circ} \mathrm{C}\right)$.

At the leaf level, we measured the leaf surface air temperature and humidity with LI-6400 XT gas exchange apparatus; for the whole plant/canopy level, we measured the canopy air temperature and the relative canopy air humidity with the HMP45D sensors (Vaisala, Helsinki, Finland) of the IMKO automatic weather station.

\subsubsection{Determination of canopy bulk stomatal conductance}

We calculated the canopy bulk stomatal conductance $\left(G_{c}\right)$ from micrometeorological and sap flow data using inversion of the Penman-Monteith equation (Monteith and Unsworth, 1990; eq. 3),

$$
G_{c}=\frac{\lambda E T \cdot \gamma \cdot G_{a}}{\Delta\left(R_{n}-S\right)+\rho_{a} C_{p} V P D \cdot G_{a}-(\Delta+\gamma) \cdot \lambda E T} .
$$

where $\lambda$ is the latent heat of vaporization of water $(\mathrm{MJ} / \mathrm{kg}) ; E T$ is canopy transpiration $(\mathrm{mm} / \mathrm{s}) ; \gamma$ is psychrometer constant $(\mathrm{kPa} / \mathrm{K}) ; G_{a}$ is the aerodynamic conductance $(\mathrm{mm} / \mathrm{s}) ; \Delta$ is gradient of the water saturation vapor pressure curve $(\mathrm{kPa} / \mathrm{K}) ; R_{n}$ is net radiation $\left(\mathrm{W} / \mathrm{m}^{2}\right) ; S$ is soil heat flux $\left(\mathrm{W} / \mathrm{m}^{2}\right) ; \rho_{a}$ is the air density $\left(\mathrm{kg} / \mathrm{m}^{3}\right) ;$ and $C_{p}$ is the specific heat of dry air at constant pressure $(\mathrm{MJ} /($ $\mathrm{kg} \cdot \mathrm{K})$ ). Assuming neutral stability conditions, $G_{a}$ can be computed as eq. 4 ,

$$
G_{a}=\frac{k^{2} u}{\ln \left((z-d) /\left(h_{c}-d\right)\right) \ln \left((z-d) / z_{0}\right)} .
$$

where $k$ is the von Karman constant $(0.41) ; z$ is the reference height $(\mathrm{m}) ; u$ is the wind speed at the reference height $(\mathrm{m} / \mathrm{s}) ; h_{c}$ is the mean crop height $(\mathrm{m}) ; d$ is the zero plane displacement $(\mathrm{m})$, approximated as $0.67 h_{c}$; and $z_{0}$ is the roughness length of the crop relative to momentum transfer (m), approximated as $0.13 h_{c}$.

\section{Results}

\subsection{Seasonal variations in environmental variables}

Seasonal variations in the main atmospheric and soil environmental conditions during the period of sap flow measurements are shown in Fig. 1. Solar radiation $\left(R_{n}\right)$ was very high, with a halfhourly maximum value of $941.3 \mathrm{~W} / \mathrm{m}^{2}$ and daily average of $138.8 \mathrm{~W} / \mathrm{m}^{2}$ (Fig. 1a). The daily mean air temperature $\left(T_{a}\right)$ was $21.3^{\circ} \mathrm{C}$, and ranged from 14.8 to $27.4^{\circ} \mathrm{C}$ (Fig. 1b). The relative humidity 
$(R H)$ ranged from $10.9 \%$ to $95.7 \%$ with a mean value of $59.7 \%$ (Fig. 1c), and was strongly influenced by the precipitation and irrigation events. The mean wind velocity $(u)$ was $1.35 \mathrm{~m} / \mathrm{s}$ and usually under $5 \mathrm{~m} / \mathrm{s}$ (Fig. 1d). Soil moisture $(\theta)$ (within the upper $50 \mathrm{~cm}$ of soil) varied considerably (ranged from 0.21 to $0.37 \mathrm{~m}^{3} / \mathrm{m}^{3}$ ) throughout the measurement period (Fig. 1e), responding to irrigation events. Throughout the measurement sap flow period (Julian days 189 to 252), however, we maintained well-watered conditions for the maize. Total precipitation for the measurement period was $13 \mathrm{~mm}$ (three rainfall events). During the measurement period, we irrigated the field three times with a total of about $315 \mathrm{~mm}$.

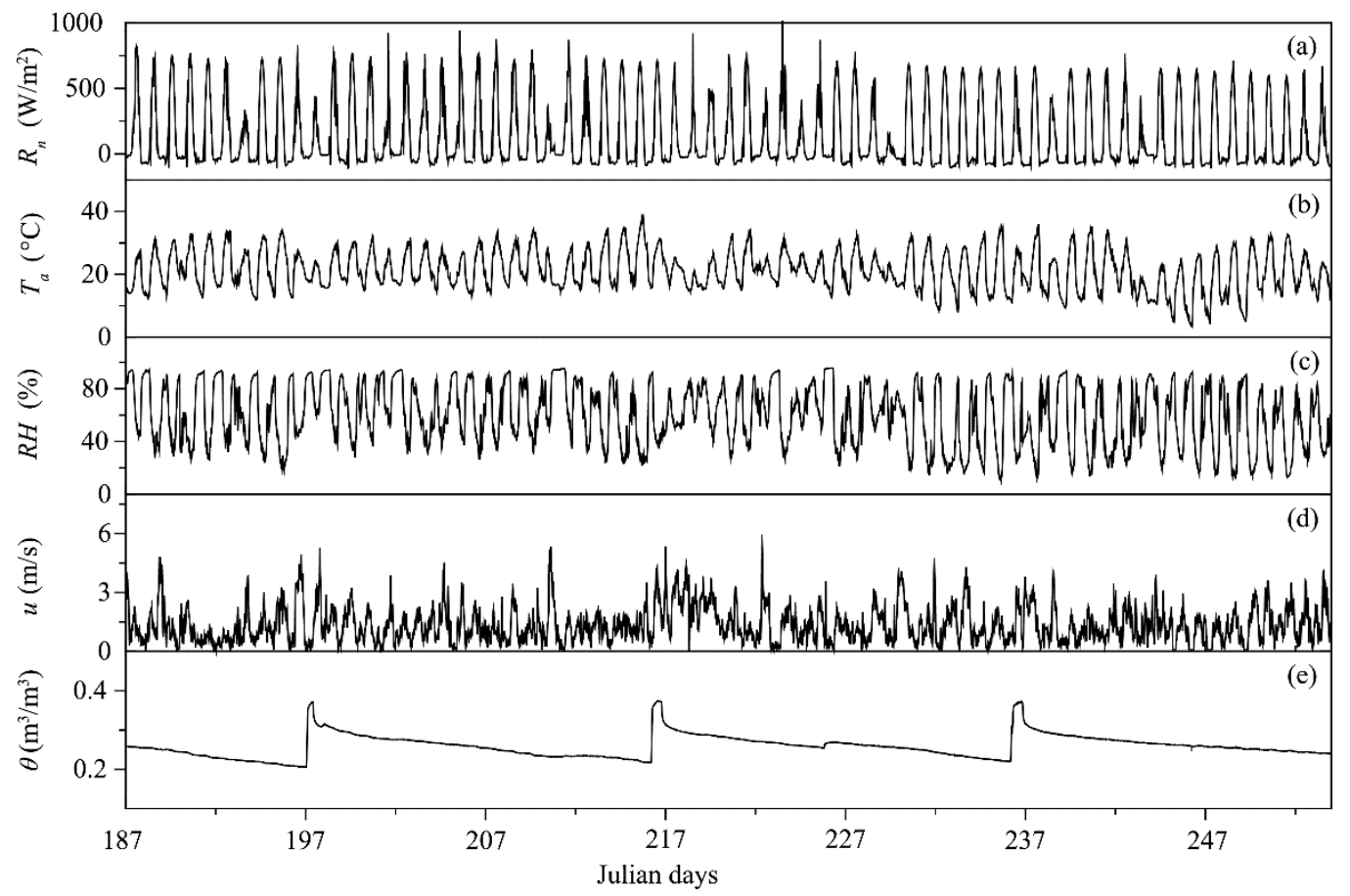

Fig. 1 Half-hourly time series of net radiation $\left(R_{n} ; \mathrm{a}\right)$, air temperature $\left(T_{a} ; \mathrm{b}\right)$, relative humidity $(R H$; c), wind $\operatorname{speed}(u ; \mathrm{d})$, and soil moisture $(\theta ; \mathrm{e})$ during the measurement period

\subsection{Diurnal patterns of transpiration at leaf scale}

Diurnal time courses of transpiration $\left(T_{1}\right)$ and leaf-to-air VPD from the gas exchange apparatus at the leaf level on Julian days 188-189 and 218-219 are presented in Figs. 2a and b, respectively.

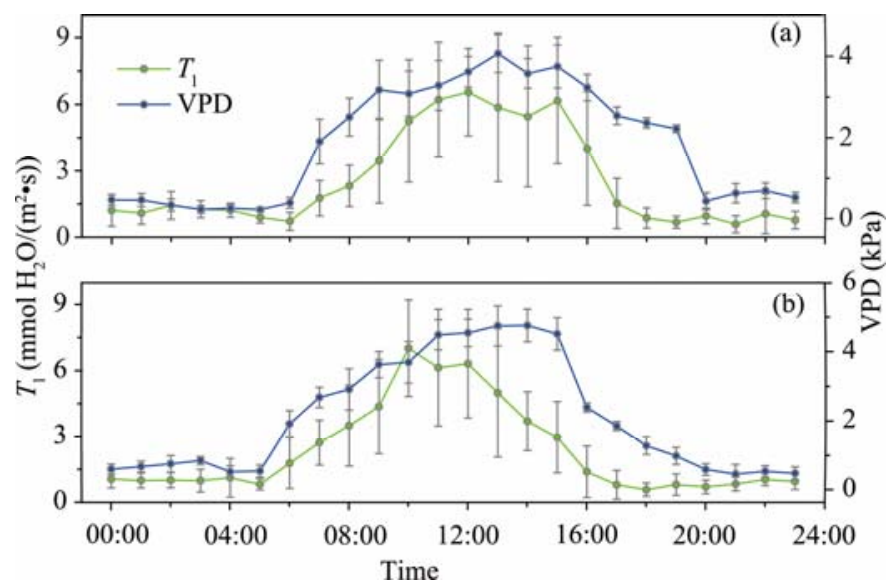

Fig. 2 Averaged diurnal course of transpiration $T_{1}$ and leaf-to-air vapor pressure deficit (VPD) at leaf level on Julian days of 188-189 (a) and 218-219 (b). Error bars represent the standard deviation of replicate measurements on different leaves. 
The average hourly leaf transpiration rate and VPD exhibited a similar daily patterns, being lowest at sunrise and increasing to a maximum at around 12:00 (local time, hereinafter referred to as same). Gas exchange measurements at leaf level, however, indicate a temporal lag between transpiration and VPD, suggesting that stomata regulate transpiration to some extent at higher VPD in the daytime, and weak midday stomatal closure (at higher VPD) seems to have occurred on both measurements.

Moreover, the magnitude of transpiration occurring during the nocturnal hours (20:00-06:00) remained relatively stable throughout the nighttime, and was considerably lower than that during the daytime (06:00-20:00). The mean nighttime transpiration rate $\left(0.99 \pm 0.44 \mathrm{mmol} \mathrm{H} \mathrm{H}_{2} \mathrm{O} /\left(\mathrm{m}^{2} \cdot \mathrm{s}\right)\right)$ was about $27 \%$ of the daytime rate $\left(3.71 \pm 1.78 \mathrm{mmol} \mathrm{H}_{2} \mathrm{O} /\left(\mathrm{m}^{2} \cdot \mathrm{s}\right)\right)$. This can be partly explained by the evidence that the nighttime VPD $(0.56 \pm 0.17 \mathrm{kPa})$ was much lower than the daytime VPD $(3.18 \pm 0.40 \mathrm{kPa})$.

\subsection{Diurnal patterns of whole plant transpiration}

Figure 3 shows the average half-hourly diurnal patterns of whole plant transpiration rate $\left(J_{S}\right)$ from sap flow measurement (i.e., averaged across the sampled six plants \pm one standard deviation) (Fig. 3a) and air VPD (Fig. 3b) at the top canopy during the measured period from Julian day 189-252. $J_{s}$ in maize and the ambient VPD had distinct diurnal variations which were triggered mainly by solar radiation (greater solar radiation resulting in higher VPD and greater $J_{s}$ ). However, the diurnal VPD trend lagged clearly behind $J_{s}$ by about $2 \mathrm{~h}$. For example, $J_{s}$ increased gradually after 06:00, peaked $(75.21 \pm 24.90 \mathrm{~g} / \mathrm{h})$ at about 11:30, then gradually decreased until 18:30, and stabilized over night from about 19:00 to 06:00 next day; in contrast, VPD peaked $(2.74 \pm 1.02 \mathrm{kPa})$ at about 14:00, decreased linearly until 18:00, and then gradually dropped to its lowest level $(0.32 \pm 0.25 \mathrm{kPa})$ before predawn (at about 05:00) next day.
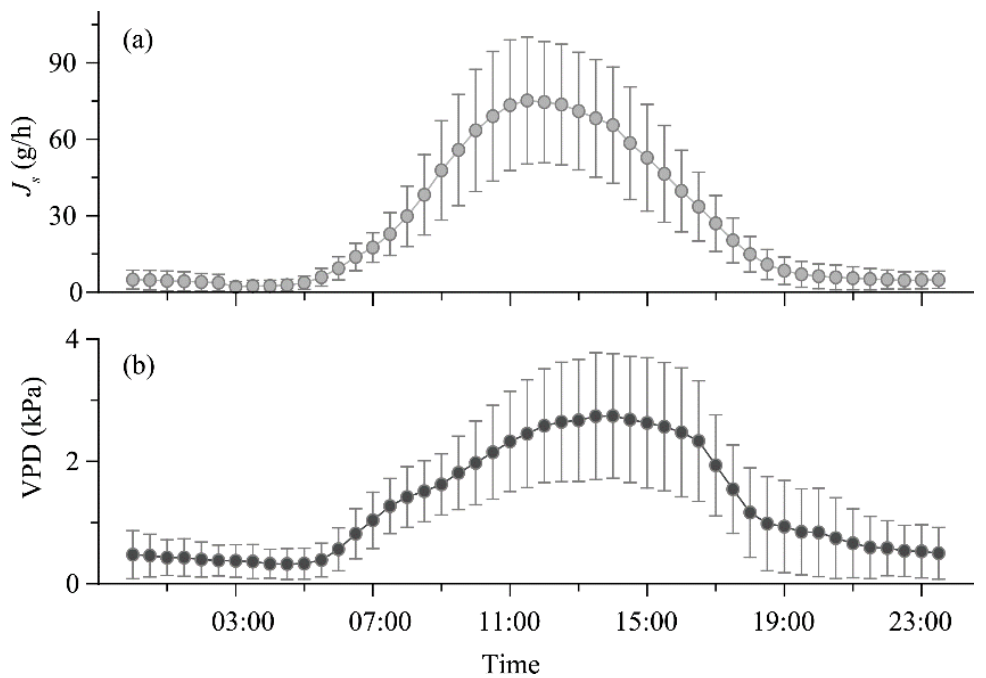

Fig. 3 Averaged diurnal course of whole plant transpiration rate $\left(J_{s}\right.$; a) and vapor pressure deficit (VPD) at the top of canopy (b) during the observed period from Julian days 189 to 252 . Error bars represent the standard deviation of replicate measurements on different leaves.

Whole plant transpiration rate $\left(J_{s}\right)$ was generally much lower at night (mean value of $4.66 \pm 3.60$ $\mathrm{g} / \mathrm{h})$, only about $10 \%$ of the values during the daytime $(45.12 \pm 16.67 \mathrm{~g} / \mathrm{h})$, but the magnitude of cumulated transpiration at night was not trivial (about $0.5 \mathrm{~mm}$ in height), exceeded $8 \%$ of the daytime value. The corresponding nighttime VPD averaged $0.52 \pm 0.41 \mathrm{kPa}$ and was approximately $27 \%$ of the daytime value $(1.95 \pm 0.77 \mathrm{kPa})$.

\section{4 Responses of daytime transpiration and stomatal conductance to VPD}

We analyzed the daytime data by plotting the instantaneous transpiration/stomatal conductance against leaf-to-air VPD at the leaf level for both measurements and found that the response of leaf 
transpiration $\left(T_{l d}\right)$ to increasing leaf-to-air VPD could be described as two linear regressions, indicating a significant positive response of $T_{l d}$ to $\operatorname{VPD}\left(R^{2}=0.51 ; P<0.05\right)$ at lower $\operatorname{VPD}(<3.5 \mathrm{kPa})$ (Fig. 4a) and a negative response at higher values $(\geq 3.5 \mathrm{kPa})$ (Fig. 4b). The transition point (the limiting maximum transpiration rate reached at a VPD of $3.5 \mathrm{kPa}$ ) divided the response of $T_{l d}$ to VPD into two distinct groups, suggesting that, to a large extent, the 'patchy' stomatal closure (i.e. feedforward response) (Farquhar, 1978; Bunce, 1996) appeared when leaf-to-air VPD was greater than about $3.5 \mathrm{kPa}$. This conclusion is consistent with the leaf level observations of Hirasawa and Hsiao (1999), and Ray et al. (2002).
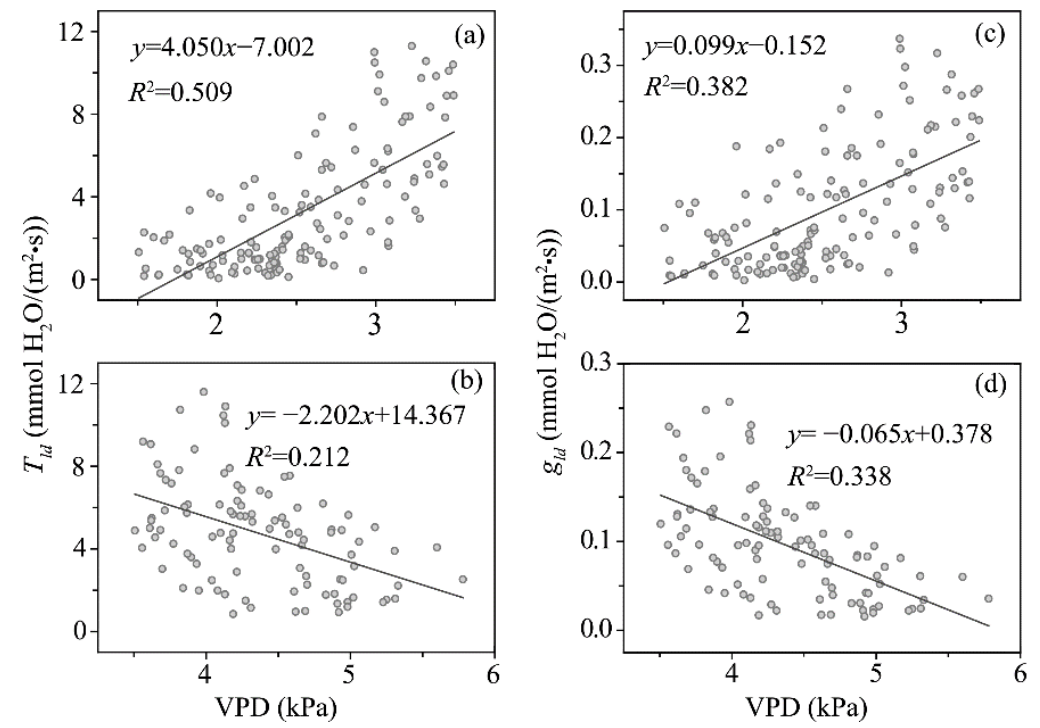

Fig. 4 Daytime leaf transpiration rates $\left(T_{l d}\right.$; a, b) and stomatal conductance $\left(g_{l d} ; \mathrm{c}, \mathrm{d}\right)$ of maize in response to leafto-air VPD when VPD was below $3.5 \mathrm{kPa}(\mathrm{a}, \mathrm{c})$, and above $3.5 \mathrm{kPa}(\mathrm{b}, \mathrm{d})$, respectively

The data from the gas exchange apparatus measurements also showed that the response of leaf stomatal conductance $\left(g_{l d}\right)$ to leaf-to-air VPD was consistent with transpiration response observed during the daytime, the $T_{l d}$ and $g_{l d}$ both increased linearly as VPD increased at values lower than approximately $3.5 \mathrm{kPa}$ (Fig. 4c), and by contrast, both decreased as VPD increased at higher values $\left(\geq 3.5 \mathrm{kPa}\right.$ ) (Fig. 4d). The similar responses of $T_{l d}$ and $g_{l d}$ to VPD further demonstrated that the traditional evidence of a 'feedforward' response worked properly through stomatal regulation, in which transpiration and stomatal conductance decreases with increasing VPD (Farquhar, 1978; Bunce, 1996).

In comparison with the transpiration to VPD at leaf level, however, we observed a strong and significant positive linear relationship $\left(R^{2}=0.765 ; P<0.05\right)$ between whole plant transpiration $\left(J_{s d}\right)$ and air VPD across a wide range throughout the daytime (Fig. 5a). There was no statistical transition point of transpiration response to VPD. Moreover, there was no statistically significant
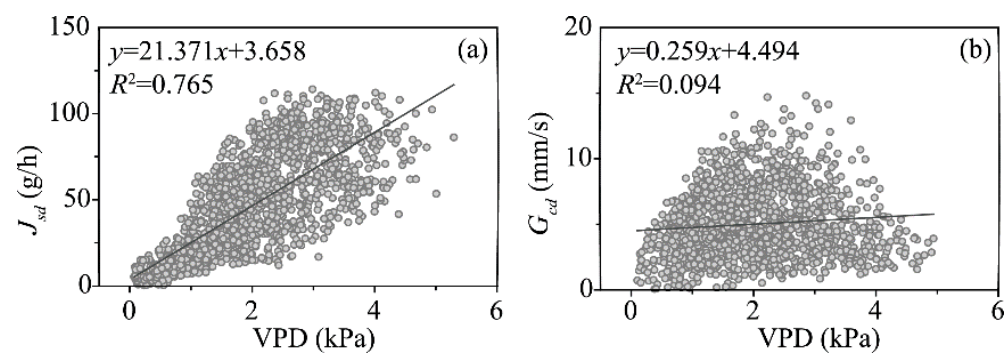

Fig. 5 Daytime half-hourly whole plant transpiration rates $\left(J_{s d}\right.$; a) and canopy bulk stomatal conductance $\left(G_{c d}\right.$; b) of maize in response to air VPD at top of canopy 
relationship between canopy conductance $\left(G_{c d}\right)$ and VPD (Fig. 5b). It is important to note, however, that a limiting maximum $G_{c d}$ was commonly reached at a VPD of about $3.0 \mathrm{kPa}$, above which there was a general trend of decreased daytime $G_{c d}$ with increased VPD (Fig. 5b). The evidences showed that whole plant transpiration was more responsive to VPD, and conversely, the corresponding $G_{c d}$ was relatively unresponsive to changes in VPD, indicating that the canopy transpiration was strongly VPD-dependent, although other limiting factors (environmental and physiological) played a significant role in $J_{s d}$ (Bunce, 1996), in conjunction with stomata regulation.

\subsection{Responses of nighttime transpiration and stomatal conductance to VPD}

We investigated the role of VPD in driving nighttime maize transpiration at both leaf $\left(T_{l n}\right)$ and whole plant $\left(J_{s n}\right)$ levels. The information presented here clearly demonstrates that nighttime leaf transpiration (Fig. 6a) was more responsive to leaf-to-air VPD than daytime leaf transpiration (Fig. 4a). Changes in VPD can explain about $69 \%$ and $64 \%$, respectively, of the nighttime variations in transpiration at the leaf (Fig. 6a) and whole plant levels (Fig. 7a).
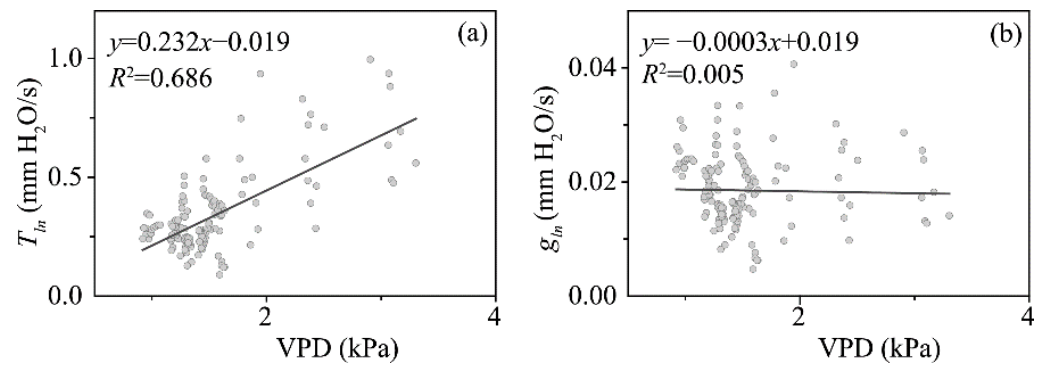

Fig. 6 Nighttime leaf transpiration rates $\left(T_{l n} ; \mathrm{a}\right)$ and leaf stomatal conductance $(g$ ln; $\mathrm{b})$ of maize in response to leaf-to-air VPD

We also found that stomatal conductance at both the leaf $\left(g_{l n}\right)$ and canopy $\left(G_{c n}\right)$ levels were quite insensitive to changes in VPD (Figs. 6a and 7b). Therefore, we can conclude that the nighttime transpiration of maize depends, to a large extent, on the driving vapor gradient between the leaf and the atmosphere (i.e. VPD), and that nighttime stomatal conductance scattered against VPD on both scales, which was probably associated with circadian rhythms (Barbour and Buckley, 2007) or boundary layer mixing (Collatz et al., 1991).
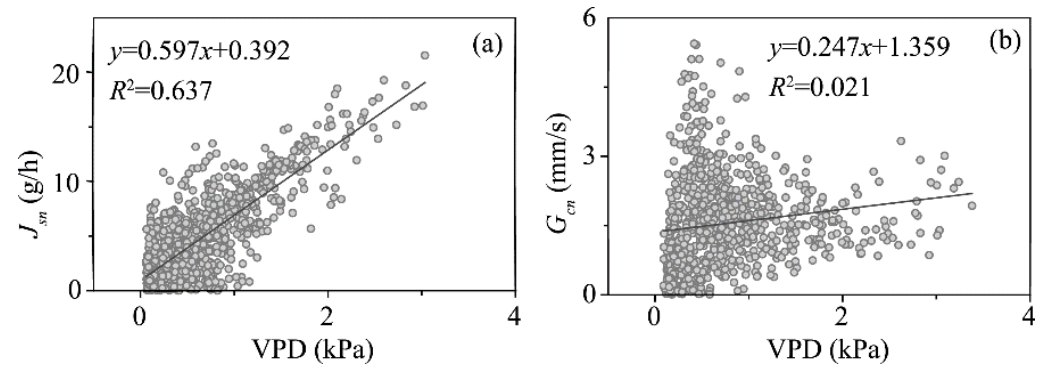

Fig. 7 Nighttime half-hourly whole plant transpiration rate $\left(J_{s n}\right.$; a) and canopy bulk stomatal conductance $\left(G_{c n}\right.$; b) of maize in response to air VPD

\subsection{Responses of daily transpiration and canopy conductance to VPD}

Over the long term (the period of sap flow measurement from Julian day 189 to 252), the averaged half-hourly whole plant transpiration $\left(J_{s m}\right)$ from six sap flow measurements varied commonly in concordance with the fluctuation of air VPD (Fig. 8). The averaged half-hourly $J_{s}$ varied from 8.45 to $43.00 \mathrm{~g} / \mathrm{h}$ with a mean value of $25.73 \mathrm{~g} / \mathrm{h}$ during the measurement period, whereas their corresponding air VPD ranged from about 0.45 to $2.55 \mathrm{kPa}$ with a mean of about $1.26 \mathrm{kPa}$. The fluctuations of $J_{s}$ and VPD are mainly attributed to lower solar radiation associated with rainfall events or cloudy days. 


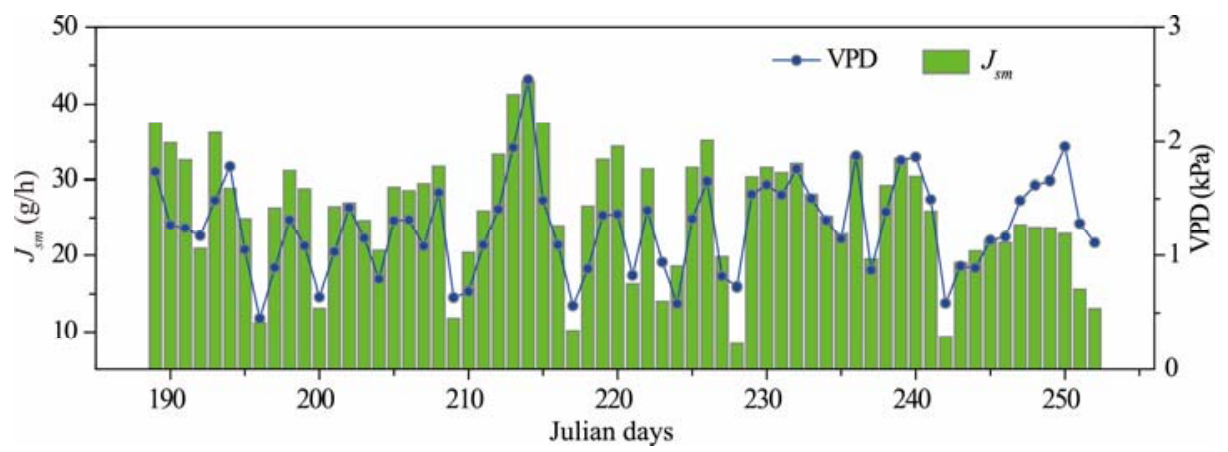

Fig. 8 Daily variations in average half-hourly whole plant transpiration rate $\left(J_{s m}\right)$ and their corresponding air VPD

We analyzed the relationship between the daily average whole plant transpiration $\left(J_{s m}\right)$ and mean daily VPD across the sap flow measurement periods. A strong and significant linear relationship $\left(R^{2} \approx 0.78 ; P<0.05\right)$ appeared between $J_{s m}$ and VPD (Fig. 9a), suggesting that the $J_{s m}$ was highly responsive to variation in VPD at a daily scale. In contrast, no linear relationship was found between daily canopy bulk conductance $\left(G_{c m}\right)$ and VPD (Fig. 9b). However, there were two roughly distinguished trends for increased $G_{c m}$ with increased $V P D$ when VPD increased to about $1.7 \mathrm{kPa}$, and decreased $G_{c m}$ with increased VPD when VPD was above $1.7 \mathrm{kPa}$. It is possible that the negative feedbacks work by stomatal patchy closure at a daily scale when the mean daily VPD was higher than approximately $1.7 \mathrm{kPa}$.
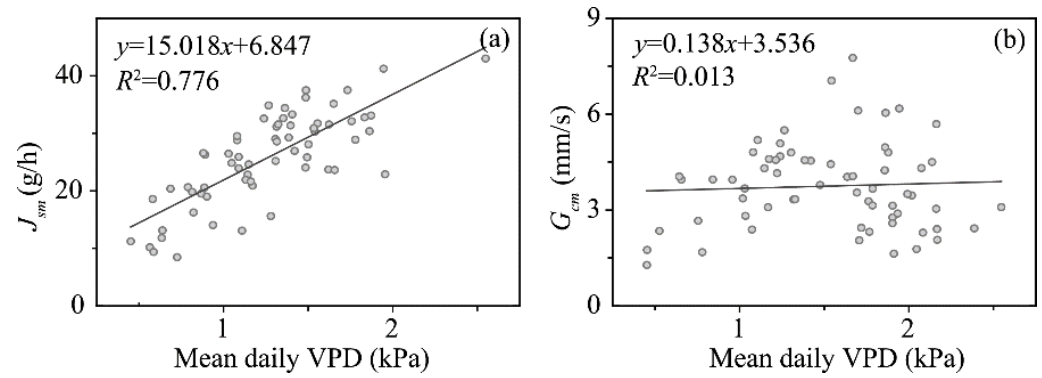

Fig. 9 Averaged daily transpiration $\left(J_{s m} ;\right.$ a) and mean canopy bulk stomatal conductance $\left(G_{c m}\right.$; b) in response to mean air VPD

\section{Discussion}

The rate of transpiration is governed by the magnitude of the vapor pressure deficit between the leaf and the surrounding air, and is also regulated by the leaf stomatal conductance (Jones, 1998; Taiz and Zeiger, 2002). A number of studies have shown that the response of plant transpiration to VPD falls into one of three categories (Grantz, 1990; Monteith, 1995; Franks et al., 1997; Oren et al., 1999; Fletcher et al., 2007; Mott and Peak, 2010; Shekoofa et al., 2014): at low VPD values, as VPD increases, stomatal conductance is high and transpiration increase; at intermediate VPD values, as VPD increases, transpiration remains relatively constant because stomatal conductance declines with increasing VPD; and at high VPD values, as VPD increases, stomatal conductance is more extreme and transpiration declines with increasing VPD. Furthermore, McNaughton and Jarvis (1991), and Mott and Peak (2010) demonstrated that increasing scale leads to an increase in the number of negative feedback paths that stabilize the system and diminish the sensitivity of transpiration to the changes in VPD.

The effects of spatial scale on VPD control of transpiration and the limited transpiration rate under a high VPD have been reported for maize under different environments (Hirasawa and Hsiao, 1999; Ray et al., 2002; Yang et al., 2012; Gholipoor et al., 2013; Choudhary et al., 2015), which were confirmed by our study that the response of maize transpiration to VPD differs considerably at different spatial and temporary levels under arid environmental climate and well-watered 
conditions. At the leaf level, the maize plant exhibits a breakpoint (about $3.5 \mathrm{kPa}$ ) in the transpiration response to VPD. In contrast, there is no defined breakpoint at the whole plant level, indicating that the mechanism of the limited transpiration trait gradually vanishes at an increasing spatial scale under conditions that are not water-limited. We attributed these disparities in the transpiration responses to VPD at different spatial scales to two possible causes. First, the micrometeorological conditions (i.e. VPD, boundary layer mixing, etc.) in the leaf cuvette of LI6400 gas exchange system differed generally from those in whole plant or canopy, resulting in variations in gas exchange properties between the leaf level and whole plant level under field conditions. Second, the individual leaves from canopy top to bottom were exposed to vastly different environmental conditions, which apparently triggered highly varied transpiration responses. With respect to temporal scales, the responsiveness of transpiration to VPD increased to some extent as the temporary scale was broadened. The reasons for this are similar to the variability in transpiration responses to VPD at different spatial scale.

It is noteworthy, however, that the maize also had a breakpoint in the stomatal conductance response to VPD at different spatial levels during the daytime, likely stemming from the discrepancies between the stomatal conductance and canopy conductance, and between leaf boundary-layer conductance and surface-layer conductance (Collatz et al., 1991; McNaughton and Jarvis, 1991; Monteith, 1995; Takagi et al., 1998; Mott, 2007; Yang et al., 2012; Choudhary et al., 2015). While during the period of nighttime, transpiration at night is theoretically controlled by atmospheric VPD and is free of stomatal conductance regulation (Jarvis and McNaughton, 1986; Jones, 1998). However, our results demonstrated there are nighttime stomatal conductance of maize was unresponsive to VPD across spatial and temporal scales. Also, nighttime stomatal conductance shifted decreasingly from small spatio-temporal level to large one, indicating the transpiration of maize under well-watered conditions can be limited by low stomatal conductance at high VPD. These results are similar to the findings of Barbour and Bucklay (2007) for Ricinus communis plant, but differ from the findings of Mott and Peak (2010) for Tradescantia pallida and Bucci et al. (2004) for tropical savanna woody species, mostly due to differences in the response of transpiration to VPD, or stomatal conductance to VPD for different species under different environment conditions.

The clear message from the above discussions is that the limited transpiration rate of the maize plant is spatio-temporal dependent because of the complex interactions among transpiration, stomatal conductance and the ambient VPD. These interactions are non-linear because of multiple mutual influences and feedback at different spatio-temporal scales (McNaughton and Jarvis, 1991; Jones, 1998). So we highly recommend that the effects of spatial and temporal scales on the response of transpiration to VPD must be taken into account to quantify the limited-transpiration trait of the maize plant at high VPD.

\section{Conclusions}

The maize transpiration at leaf, whole plant and canopy scales were measured independently in situ under arid climatic and well-watered conditions. The responses of transpiration to VPD at different temporal scales (i.e. instantaneous, half-hourly and daily scales) for different spatial scales were discussed. Our results demonstrate that the maize transpiration response to VPD is -dependent.

For spatial scale, the transpiration response to VPD shows an apparent breakpoint at approximately $3.5 \mathrm{kPa}$ VPD, mostly due to partial stomatal closure at high VPD (negative feedback) in the daytime; while maize transpiration is not virtually restricted under high VPD at the whole plant level and canopy scales. However, the limiting canopy bulk stomatal conductance occurred at VPD values of approximately $3.0 \mathrm{kPa}$ and $1.7 \mathrm{kPa}$ at half-hourly and daily scales, respectively, although good correlation could not be established between the canopy conductance and VPD, indicating maize transpiration is controlled by stomatal conductance at high VPD under even wellwatered conditions in the arid environments. The temporal responses of maize transpiration are similar to those at spatial scales.

In reality, the maize transpiration is linked to the combined influences of climate-driven variables that a crop may experience in the field and by stomatal regulation and a better understanding of the 
mechanism of transpiration regulation is needed to account for the effect of spatio-temporal scales in practice. Our results provide an improved understanding of this phenomenon, which could assist physiologists, plant breeders and water resources managers to better take advantage of maize's transpiration restriction trait, and to better estimate plant transpiration using the empirical models for stomatal conductance at different spatio-temporal scales, and then in the effort to improve the understanding of the combined influences of VPD and stomatal regulation in arid environment. A restricted transpiration at high VPD may be linked to anatomical, physiological, or ecological features and these proximate controls deserve further studies.

\section{Acknowledgements}

This work was funded by the National Science Fund for Distinguished Young Scholars (41125002) and the Chinese National Natural Science Foundation (41271036). We thank Dr. JIN Bowen and ZHAO Linwen for field measurements of plant sap flow and leaf gas exchange. We also thank anonymous reviewers for their helpful and constructive comments.

\section{References}

Baker J M, Van Bavel C H M. 1987. Measurement of mass flow of water in the stems of herbaceous plants. Plant, Cell and Environment, 10(9): 777-782.

Barbour M M, Buckley T N. 2007. The stomatal response to evaporative demand persists at night in Ricinus communis plants with high nocturnal conductance. Plant, Cell and Environment, 30(6): 711-721.

Belko N, Zaman-Allah M, Diop N N, et al. 2013. Restriction of transpiration rate under high vapour pressure deficit and nonlimiting water conditions is important for terminal drought tolerance in cowpea. Plant Biology, 15(2): 304-316.

Bucci S J, Scholz F G, Goldstein G, et al. 2004. Processes preventing nocturnal equilibration between leaf and soil water potential in tropical savanna woody species. Tree Physiology, 24(10): 1119-1127.

Bunce J A. 1981. Comparative responses of leaf conductance to humidity in single attached leaves. Journal of Experimental Botany, 32(3): 629-634.

Bunce J A. 1996. Does transpiration control stomatal responses to water vapour pressure deficit? Plant, Cell and Environment, 19(2): 131-135.

Chen X, Li B L, Li Q, et al. 2012. Spatio-temporal pattern and changes of evapotranspiration in arid Central Asia and Xinjiang of China. Journal of Arid Land, 4(1): 105-112.

Choudhary S, Sinclair T R, Messina C D, et al. 2015. Inhibitor screen for limited-transpiration trait among maize hybrids. Environmental and Experimental Botany, 109: 161-167.

Collatz G J, Ball J T, Grivert C, et al. 1991. Physiological and environmental regulation of stomatal conductance, photosynthesis and transpiration: a model that includes a laminar boundary layer. Agricultural and Forest Meteorology, 54(2-4): 107-136.

Devi M J, Sinclair T R, Vadez V. 2010. Genotypic variation in peanut for transpiration response to vapor pressure deficit. Crop Science, 50(1): 191-196.

Farquhar G D. 1978. Feedforward responses of stomata to humidity. Australian Journal of Plant Physiology, 5(8): 787-800.

Fletcher A L, Sinclair T R, Allen Jr L H. 2007. Transpiration responses to vapor pressure deficit in well watered 'slow-wilting' and commercial soybean. Environmental and Experimental Botany, 61(2): 145-151.

Franks P J, Cowan I R, Farquhar G D. 1997. The apparent feedforward response of stomata to air vapour pressure deficit: information revealed by different experimental procedures with two rainforest trees. Plant, Cell and Environment, 20(1): 142-145.

Gholipoor M, Choudhary S, Sinclair T R, et al. 2013. Transpiration response of maize hybrids to atmospheric vapour pressure deficit. Journal of Agronomy and Crop Science, 199(3): 155-160.

Gholipoor M, Prasad P V V, Mutava R N, et al. 2010. Genetic variability of transpiration response to vapor pressure deficit among sorghum genotypes. Field Crops Research, 119(1): 85-90.

Gilbert M E, Holbrook N M, Zwieniecki M A, et al. 2011. Field confirmation of genetic variation in soybean transpiration 
response to vapor pressure deficit and photosynthetic compensation. Field Crops Research, 124(1): 85-92.

Grantz D A. 1990. Plant response to atmospheric humidity. Plant, Cell and Environment, 13(7): 667-679.

Hirasawa T, Hsiao T C. 1999. Some characteristics of reduced leaf photosynthesis at midday in maize growing in the field. Field

Crops Research, 62(1): 53-62.

Jarvis P G, McNaughton K G. 1986. Stomatal control of transpiration: scaling up from leaf to region. Advance in Ecological

Research, 15: 1-49.

Ji X B, Kang E S, Chen R S, et al. 2006. The impact of the development of water resources on environment in arid inland river basins of Hexi region, Northwestern China. Environmental Geology, 50(6): 793-801.

Ji X B, Zhao W Z, Kang E S, et al. 2011a. Carbon dioxide, water vapor, and heat fluxes over agricultural crop field in an arid oasis of Northwest China, as determined by eddy covariance. Environmental Earth Sciences, 64(3): 619-929.

Ji X B, Zhao W Z, Kang E S, et al. 2011b. Carbon dioxide exchange in an irrigated agricultural field within an oasis, Northwest China. Journal of Applied Meteorology and Climatology, 50(11): 2298-2308.

Jones H G. 1998. Stomatal control of photosynthesis and transpiration. Journal of Experimental Botany, 49(Suppl.): 387-398.

Jones P G, Thornto P K. 2003. The potential impacts of climate change on maize production in Africa and Latin America in 2055.

Global Environmental Change, 13(1): 51-59.

Kang E, Lu L, Xu Z. 2007. Vegetation and carbon sequestration and their relation to water resources in an inland river basin of Northwest China. Journal of Environmental Management, 85(3): 702-710.

Kholová J, Hash C T, Kumar P L, et al. 2010. Terminal drought-tolerant pear millet [Pennisetum glaucum (L.) R. Br.] have high leaf ABA and limit transpiration at high vapour pressure deficit. Journal of Experimental Botany, 61(5): 1431-1440.

McNaughton K G, Jarvis P G. 1991. Effects of spatial scale on stomatal control of transpiration. Agricultural and Forest Meteorology, 54(2-4): 279-302.

Monteith J L. 1995. A reinterpretation of stomatal responses to humidity. Plant, Cell and Environment, 18(4): 357-364.

Monteith J L, Unsworth M. 1990. Principles of Environmental Physics (2 ${ }^{\text {nd }}$ ed.). London: Edward Arnold, 195-198.

Mott K A. 2007. Leaf hydraulic conductivity and stomatal responses to humidity in amphistomatous leaves. Plant, Cell and Environment, 30(11): 1444-1449.

Mott K A, Parkhurst D F. 1991. Stomatal response to humidity in air and helox. Plant, Cell and Environment, 14(5): 509-515.

Mott K A, Peak D. 2010. Stomatal responses to humidity and temperature in darkness. Plant, Cell and Environment, 30(7): 1084-1090.

Oren R, Sperry J S, Katul G G, et al. 1999. Survey and synthesis of intra- and interspecific variation in stomatal sensitivity to vapor pressure deficit. Plant, Cell and Environment, 22(12): 1515-1526.

Passioura J B, Angus J F. 2010. Improving productivity of crops in water-limited environments. Advance in Agronomy, 106: $37-75$.

Ray J D, Gesch R W, Sinclair T R, et al. 2002. The effect of vapor pressure deficit on maize transpiration response to a drying soil. Plant and Soil, 239(1): 113-121.

Rebetzke G J, Condon A G, Richards R A, et al. 2003. Gene action for leaf conductance in three wheat crosses. Australian Journal of Agricultural Research, 54(4): 381-387.

Riar M K, Sinclair T R, Vara Prasad P V. 2015. Persistence of limited-transpiration-rate trait in sorghum at high temperature. Environmental and Experimental Botany, 115: 58-62.

Sadok W, Sinclair T R. 2009. Genetic variability of transpiration response to vapor pressure deficit among soybean cultivars. Crop Science, 49(3): 955-960.

Sakuratani T. 1981. A heat balance method for measuring water flux in the stem of intact plants. Journal of Agricultural Meteorology, 37(1): 9-17.

Seversike T M, Sermons S M, Sinclair T R, et al. 2013. Temperature interactions with transpiration response to vapor pressure deficit among cultivated and wild soybean genotypes. Phsiologia Plantarum, 148(1): 62-73.

Shekoofa A, Balota M, Sinclair T R. 2014. Limited-transpiration trait evaluated in growth chamber and field for sorghum genotypes. Environmental and Experimental Botany, 99: 175-179. 
Shekoofa A, Devi J M, Sinclair T R, et al. 2013. Divergence in drought-resistance traits among parents of recombinant peanut inbred lines. Crop Science, 53(6): 2569-2576.

Sinclair T R, Hammer G L, van Oosterom E J. 2005. Potential yield and water-use efficiency benefits in sorghum from limited maximum transpiration rate. Functional Plant Biology, 32(10): 945-952.

Sinclair T S, Zwieniecki M A, Holbrook N M. 2008. Low leaf hydraulic conductance associated with drought tolerance in soybean. Physiologia Plantarum, 132(4): 446-451.

Taiz L, Zeiger E. 2002. Plant Physiology (3 ${ }^{\text {rd }}$ ed.). Sunderland: Sinauer Associates, 57-64.

Takagi K, Tsuboya T, Takahashi H. 1998. Diurnal hystereses of stomatal and bulk surface conductances in relation to vapor pressure deficit in a cool-temperate wetland. Agricultural and Forest Meteorology, 91(3-4): 177-191.

Yang Z J, Sinclair T R, Zhu M, et al. 2012. Temperature effect on transpiration response of maize plants to vapour pressure deficit. Environmental and Experimental Botany, 78: 157-162.

Zhang X H, Yang D G, Xiang X Y, et al. 2012. Impact of agricultural development on variation in surface runoff in arid regions: a case of the Aksu River Basin. Journal of Arid Land, 4(4): 339-410. 